\title{
COMPARATIVE STUDY OF FENTANYL, BUTORPHANOL AND NALBUPHINE IN ATTENUATION OF HAEMODYNAMIC RESPONSES IN LAPAROSCOPIC CHOLECYSTECTOMY
}

\author{
Balwinder Kaur Rekhi', Tejinderpal Kaur Grewal2, Parmod Kumar ${ }^{3}$, Simrit Kaur ${ }^{4}$, Priyanka Mehta ${ }^{5}$
}

1 Professor, Department of Anaesthesiology, GMC, Patiala, Punjab.

2Professor, Department of Anaesthesiology, GMC, Patiala, Punjab.

3 Professor and HOD, Department of Anaesthesiology, GMC, Patiala, Punjab.

${ }^{4}$ Assistant Professor, Department of Anaesthesiology, GMC, Patiala, Punjab.

53rd Year Junior Resident, Department of Anaesthesiology, GMC, Patiala, Punjab.

\section{ABSTRACT}

\section{BACKGROUND}

Numerous attempts have been made in the past to attenuate the haemodynamic responses occurring during laparoscopic cholecystectomy. The present study compared the effect of three opioids namely Butorphanol, Fentanyl and Nalbuphine in obtundation of haemodynamic responses in laparoscopic cholecystectomy in terms of Heart rate, BP (SBP, DBP and MAP) and secondary aim was to calculate duration of analgesia and sedation score.

\section{MATERIALS AND METHODS}

This was a randomised study comparing three opioid drugs- nalbuphine, fentanyl and butorphanol. It was carried out on 75 patients of either sex aged 18 - 60 years scheduled for elective laparoscopic cholecystectomy under GA. Subjects were enrolled into three groups- Group B (n=25) patients received inj. Butorphanol $25 \mathrm{mcg} / \mathrm{kg}$ IV, Group F (n= 25) received inj. Fentanyl 2 mcg/kg IV and Group $\mathrm{N}(\mathrm{n}=25)$ patients received inj. Nalbuphine $0.2 \mathrm{mg} / \mathrm{kg} 5$ minutes before the induction.

\section{RESULT}

At the time of extubation, mean MAP in Group B, F and N was 99.88, 95.32 and 97.24 respectively. This difference is highly significant when compared statistically ( $\mathrm{p}$ value is 0.005 ).

\section{CONCLUSION}

With this study, we conclude that the administration of intravenous fentanyl and nalbuphine five minutes prior to induction of anaesthesia helps in better obtundation of haemodynamic responses to laparoscopic cholecystectomy than butorphanol.

\section{KEYWORDS}

Butorphanol, Fentanyl, Nalbuphine, Laparoscopic Cholecystectomy, Pneumoperitoneum, Obtundation, Haemodynamic Response. HOW TO CITE THIS ARTICLE: Rekhi BK, Grewal TK, Kumar P, et al. Comparative study of fentanyl, butorphanol and nalbuphine in attenuation of haemodynamic responses in laparoscopic cholecystectomy. J. Evolution Med. Dent. Sci. 2018;7(17):2156-2162, DOI: $10.14260 /$ jemds/2018/483

\section{BACKGROUND}

Laparoscopic surgeries form an essence of today's surgical practice because of its magnification, dexterity, less cosmetic scar, less post-operative pain and decreased hospital stay because of decreased morbidity and mortality.(1)

However, pneumoperitoneum created to visualise intraabdominal organs along with positional changes (Reverse Trendelenburg position) results in a significant haemodynamic and respiratory changes. (2)

The cardiovascular changes are characterised by decrease in cardiac output and increase in systemic vascular resistance which in turn results in sudden tachycardia, hypertension and increased myocardial oxygen requirement. CO2 (Used for abdominal insufflation) readily absorbed from peritoneal cavity into the circulation resulting in hypercapnia. (3)

'Financial or Other Competing Interest': None.

Submission 12-03-2018, Peer Review 06-04-2018,

Acceptance 12-04-2018, Published 23-04-2018.

Corresponding Author:

Dr. Tejinderpal Kaur Grewal,

\#150, Punjabi Bagh,

Patiala,

Punjab.

E-mail: mehta.priyanka09@gmail.com

DOI: $10.14260 /$ jemds $/ 2018 / 483$
These changes though better tolerated in ASA I and II, patients can be detrimental in elderly and ASA III patients particularly with compromised cardiovascular physiology. Various surgical methods like change in nature of insufflating gas, use of low intra-abdominal pressure, use of abdominal wall lift methods have been tried to decrease the haemodynamic alterations associated with pneumoperitoneum, but all with practical limitations. (4)

The inclusion of an opioid can reduce pre-operative pain and anxiety, decrease somatic and autonomic responses to airway manipulation, improve haemodynamic stability, lower requirement for inhaled anaesthetics and provide immediate post-operative analgesia. Each drug has its advantages and disadvantages depending upon its pharmacokinetic and pharmacodynamic profile.(5)

Fentanyl has been identified as an effective agent in this regard. Fentanyl citrate is a synthetic phenylpiperidine opioid and analgesic and chemical congener of pethidine. It is 100 times more potent than morphine. It is a $\mu(\mathrm{mu})$ receptor agonist which belongs to $\mathrm{G}$ protein-coupled receptor family. Metabolism is mainly via the hepatic route and it has a high first pass metabolism.

Nalbuphine is a semi-synthetic opioid agonist-antagonist of the phenanthrene series. It is chemically related to the widely used opioid antagonist naloxone and naltrexone and the potent opioid analgesic, oxymorphone. It acts as an 
agonist at $\mathrm{K}$ (kappa) receptor and antagonist at $\mu$ (mu) receptor. Nalbuphine is a potent analgesic.(6)

Butorphanol is a synthetic opioid derivative. It is a mixed agonist-antagonist and 5 to 8 times as potent as morphine and is available only in the parenteral form. Butorphanol is agonist at $\mathrm{K}$ (kappa) receptor and mixed agonist-antagonist at $\mu(\mathrm{mu})$ receptor. Whereas duration of action of butorphanol is similar to that of morphine, its plasma $t^{1 / 2}$ is 2-3 hrs. Duration of analgesia is 3 to 4 hrs. (7)

The primary purpose of the present study is to compare the effects of Fentanyl, Nalbuphine and Butorphanol in obtundation of haemodynamic responses during laparoscopic cholecystectomy and secondary aim is to calculate duration of analgesia, sedation score and note any adverse effects.

\section{MATERIALS AND METHODS}

\section{Study Design}

A prospective, comparative, randomised study. After getting approval from the Institutional Ethical Committee, an informed consent was taken from the patient. This study was conducted on 75 patients aged between 18 - 60 years of either sex and ASA grade I and II scheduled for elective laparoscopic cholecystectomy under general anaesthesia in between June 2016 to Oct 2017.

\section{Sample Size}

The expected difference between two means is 3.82 and common within group standard deviation is 3.80 . The per group sample size that gives an $80 \%$ chance that 0.05 level test of significance found a statistically significant difference between two sample means was approximately 17 . When 3 means were compared, the approximate group size adjusted for multiple comparisons was 23 .

\section{Inclusion Criteria}

Age group between 18 - 60 years, undergoing elective laparoscopic cholecystectomy and ASA grade I and II

\section{Exclusion Criteria}

Patient's refusal, h/o bradycardia, uncontrolled diabetes mellitus, arrhythmias, renal or liver dysfunction, cardiopulmonary disease, allergic to Nalbuphine, Fentanyl or Butorphanol.

Patients were familiarised with the visual analogue scale (VAS), ${ }^{8}$ (0- No pain, 10 - Worst pain) a day before surgery.

Patients were randomly allocated using computer generated random number and by picking up a sealed envelope into three groups of 25 patients each Group B, Group F and Group N.

All the patients were kept fasting and given tab ranitidine $150 \mathrm{mg}$ and tab Lorazepam $1 \mathrm{mg}$ at $6 \mathrm{am}$ on the day of surgery.

In the operation theatre, routine monitors were attached and baseline pulse rate, systolic blood pressure, diastolic blood pressure, mean arterial pressure and saturation of peripheral oxygen $\left(\mathrm{SpO}_{2}\right)$ were recorded. AII the patients were pre-loaded with $15 \mathrm{~mL} / \mathrm{kg}$ of ringer lactate of the ringer's lactate solution and given inj. glycopyrrolate $0.2 \mathrm{mg}$.
Patients in Group B, Group F and Group N received inj. Butorphanol $25 \mathrm{mcg} / \mathrm{kg} \mathrm{IV}$, inj. Fentanyl $2 \mathrm{mcg} / \mathrm{kg}$ IV and inj. Nalbuphine $0.2 \mathrm{mg} / \mathrm{kg}$ IV respectively. AII the three drugs (Butorphanol, Fentanyl and Nalbuphine) were diluted in 10 $\mathrm{mL}$ distilled water and injected slowly 5 minutes before the induction of anaesthesia.

After 3 minutes, pre-oxygenation with $100 \%$ oxygen using a Bain's circuit and administration of study drugs, induction was done with IV propofol injection till the loss of eyelash and corneal reflex. Inj. succinylcholine IV $1.5 \mathrm{mg} / \mathrm{kg}$ was given and patients were intubated. Anaesthesia was maintained with $\mathrm{O}_{2}-\mathrm{N}_{2} \mathrm{O}$ (50\%-50\%), Isoflurane $1 \%$ and vecuronium bromide $0.1 \mathrm{mg} / \mathrm{kg}$ bolus followed by maintenance dose one-fourth of the initial dose as and when required. Positive pressure ventilation was continued. Cardiovascular parameters (Heart rate, SBP, DBP, MAP), $\mathrm{SP}_{2}$ and $\mathrm{EtCO}_{2}$ were recorded at the following points of time:

Prior to induction (baseline), at the time of endotracheal intubation, every 2 mins interval after the endotracheal intubation till 10 minutes, before the pneumoperitoneum, every 10 mins interval till 60 mins after the pneumoperitoneum, after release of carbon-dioxide (C02) and after extubation.

At the end of surgery, neuromuscular blockade was reversed with neostigmine $50 \mu \mathrm{g} / \mathrm{kg}$ and glycopyrrolate 10 $\mu \mathrm{g} / \mathrm{kg}$ intravenously. After satisfying the extubation criteria, patients were extubated and transferred to post-anaesthesia care unit (PACU). In PACU, every patient was monitored for the haemodynamic parameters (HR, SBP, DBP, MAP) and $\mathrm{SPO}_{2}$, sedation score, VAS score for pain relief and postoperative complications if any. Haemodynamic parameters (HR, SBP, DBP, MAP) and arterial 02 saturation were monitored every 10 mins post-operatively upto 90 minutes. Any incidence of complications/ adverse event was monitored for next 90 minutes. During the post-operative period, assessment of pain was done with the help of VAS score. VAS score was recorded at 15 and 30 mins, $1^{\text {st }}, 2^{\text {nd }}, 3^{\text {rd }}$ and $4^{\text {th }}$ hour and duration of analgesia was also recorded (Time interval from the intravenous drug administration upto time when VAS reaches 5). Thereafter, rescue analgesic (IV ketorolac) was given to the patient. The sedation score was assessed by University of Michigan Sedation Scale (UMSS), ${ }^{9}$ post-operatively as:

\section{University of Michigan Sedation Scale (UMSS) \\ $1=$ Awake and alert. \\ $2=$ Sedated and responding to verbal command. \\ $3=$ Sedated but responding to mild physical stimulus. \\ $4=$ Drowsy but responding to moderate physical stimulus. \\ $5=$ Very drowsy not responding to severe physical stimulus.}

\section{Statistical Analysis}

The mean comparisons between groups is done by ANOVA with post-hoc test. Categorical variables are compared between groups using Chi-square test Software used was SPSS version 17. A probability level of $p<0.05$ was considered significant. 


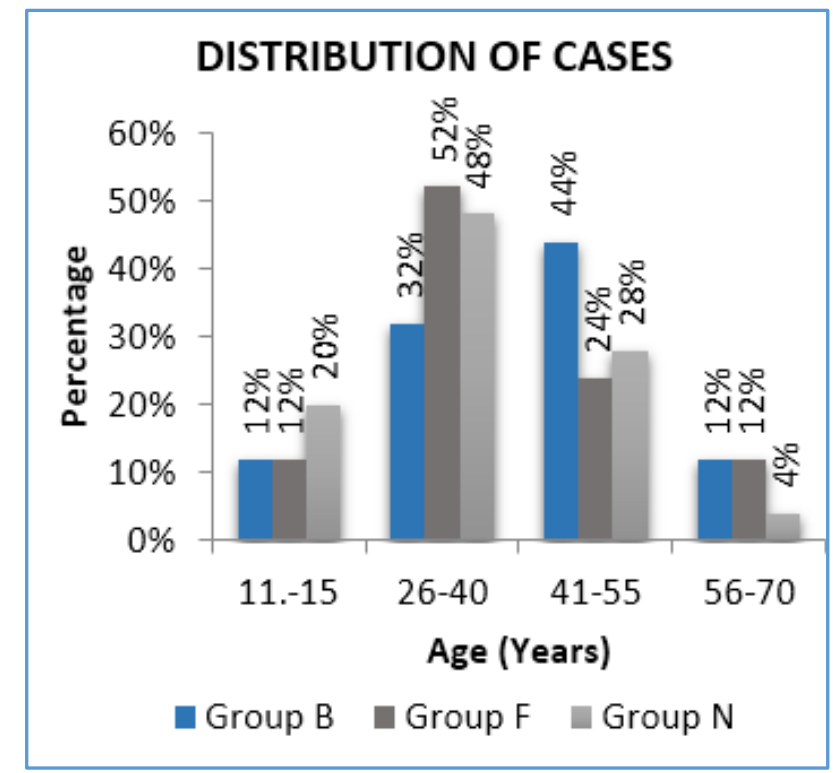

Figure 1

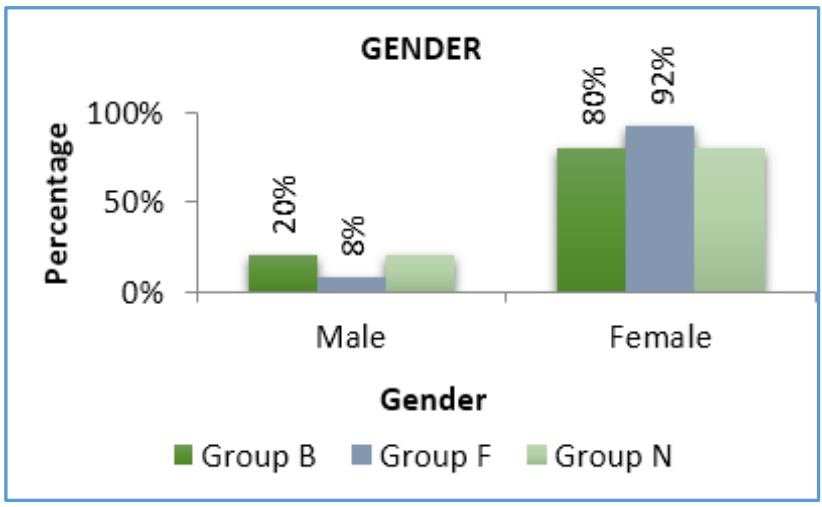

Figure 2

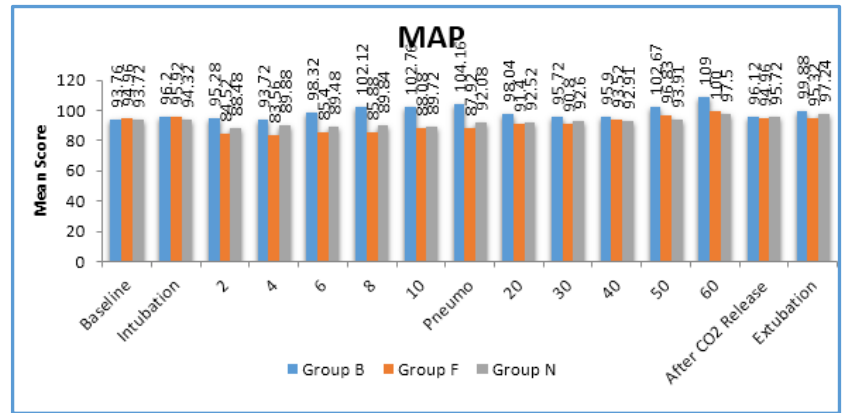

Figure 3

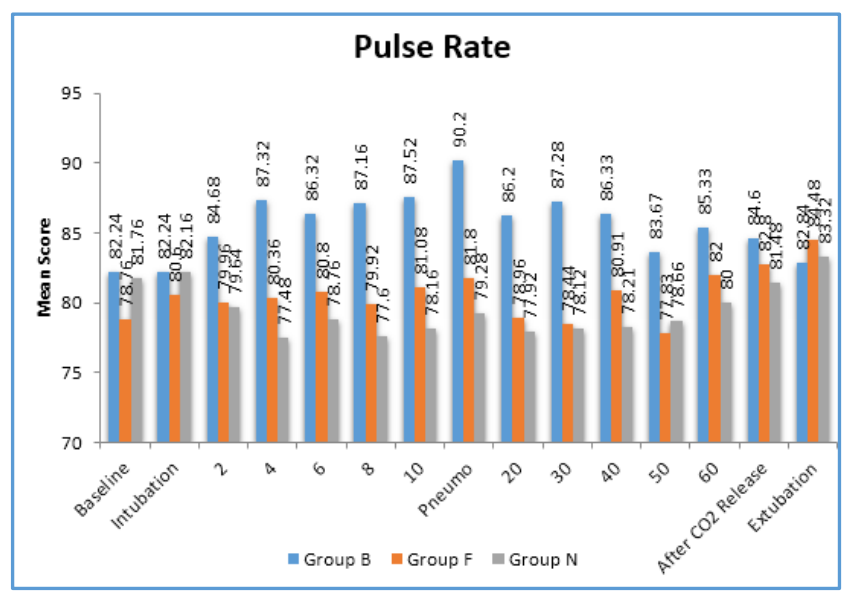

Figure 4

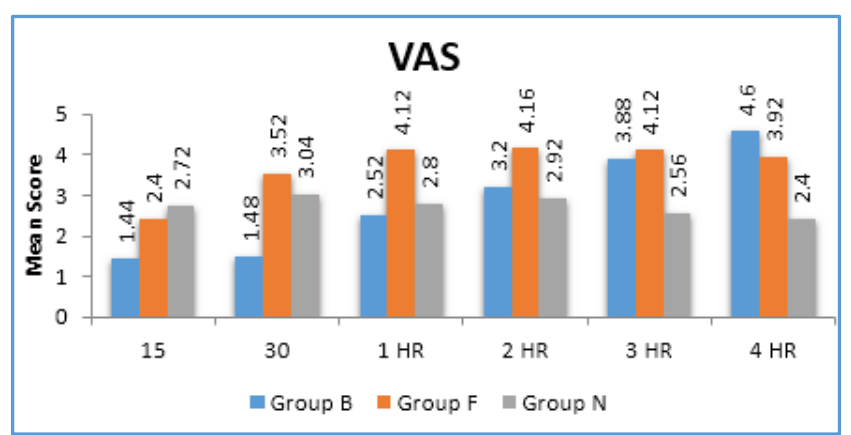

Figure 5

\begin{tabular}{|c|c|c|c|c|c|c|}
\hline \multirow{2}{*}{ Age } & \multicolumn{2}{|c|}{ Group B } & \multicolumn{2}{|c|}{ Group F } & \multicolumn{2}{|c|}{ Group N } \\
\hline & Number & Percentage & Number & Percentage & Number & Percentage \\
\hline $11-25$ & 3 & 12.0 & 3 & 12.0 & 5 & 20.0 \\
\hline $26-40$ & 8 & 32.0 & 13 & 52.0 & 12 & 48.0 \\
\hline $41-55$ & 11 & 44.0 & 6 & 24.0 & 7 & 28.0 \\
\hline $56-70$ & 3 & 12.0 & 3 & 12.0 & 1 & 4.0 \\
\hline Total & 25 & 100.0 & 25 & 100.0 & 25 & 100.0 \\
\hline Mean \pm S.D & \multicolumn{2}{|c|}{$41.20 \pm 10.92$} & \multicolumn{2}{|c|}{$38.64 \pm 12.41$} & \multicolumn{2}{|c|}{$35.84 \pm 11.49$} \\
\hline Chi-Square & \multicolumn{6}{|c|}{4.893} \\
\hline P value & \multicolumn{6}{|c|}{0.558} \\
\hline Significance & \multicolumn{6}{|c|}{ NS } \\
\hline \multicolumn{7}{|c|}{ Table 1. Age } \\
\hline
\end{tabular}

\begin{tabular}{|c|c|c|c|c|c|c|}
\hline \multirow{2}{*}{ Sex } & \multicolumn{2}{|c|}{ Group B } & \multicolumn{2}{|c|}{ Group F } & \multicolumn{2}{|c|}{ Group N } \\
\hline & Number & Percentage & Number & Percentage & Number & Percentage \\
\hline Male & 5 & 20.0 & 2 & 8.0 & 5 & 20.0 \\
\hline Female & 20 & 80.0 & 23 & 92.0 & 20 & 80.0 \\
\hline Total & 25 & 100.0 & 25 & 100.0 & 25 & 100.0 \\
\hline Chi-Square & \multicolumn{6}{|c|}{1.786} \\
\hline P value & \multicolumn{6}{|c|}{0.409} \\
\hline Significance & \multicolumn{6}{|c|}{ NS } \\
\hline \multicolumn{7}{|c|}{ Table 2. Sex } \\
\hline
\end{tabular}

Demographic profile was comparable between the three groups as shown in Fig. 1, Table 1, Fig. 2 and Table 2. 


\begin{tabular}{|c|c|c|c|c|c|c|c|c|}
\hline \multirow{2}{*}{ SBP } & Group I & Group II & Group III & \multirow{2}{*}{ P value } & Significance & B vs. F & \multirow{2}{*}{ B vs. N } & F vs. N \\
\cline { 2 - 7 } & Mean \pm S.D & Mean \pm S.D & Mean \pm S.D & & & & \\
\hline Baseline & $125.00 \pm 8.21$ & $127.16 \pm 7.76$ & $122.52 \pm 7.01$ & 0.109 & NS & 0.323 & 0.257 & 0.036 \\
\hline Intubation & $128.12 \pm 11.15$ & $128.04 \pm 6.04$ & $123.00 \pm 6.97$ & 0.052 & NS & 0.973 & 0.034 & 0.036 \\
\hline 2 & $126.72 \pm 7.77$ & $115.00 \pm 8.08$ & $115.76 \pm 9.87$ & $<0.001$ & HS & $<0.001$ & $<0.001$ & 0.756 \\
\hline 4 & $124.04 \pm 9.77$ & $111.76 \pm 8.40$ & $113.88 \pm 7.61$ & $<0.001$ & HS & $<0.001$ & $<0.001$ & 0.389 \\
\hline 6 & $126.76 \pm 13.27$ & $112.40 \pm 8.03$ & $114.24 \pm 7.61$ & $<0.001$ & HS & $<0.001$ & $<0.001$ & 0.517 \\
\hline 8 & $129.76 \pm 11.48$ & $112.84 \pm 9.54$ & $116.04 \pm 6.07$ & $<0.001$ & HS & $<0.001$ & $<0.001$ & 0.228 \\
\hline 10 & $130.56 \pm 7.81$ & $114.80 \pm 6.79$ & $117.52 \pm 5.96$ & $<0.001$ & HS & $<0.001$ & $<0.001$ & 0.168 \\
\hline Pneumo & $130.04 \pm 641$ & $116.76 \pm 7.22$ & $119.72 \pm 5.54$ & $<0.001$ & HS & $<0.001$ & $<0.001$ & 0.108 \\
\hline 20 & $124.64 \pm 7.12$ & $116.32 \pm 6.93$ & $122.72 \pm 7.04$ & $<0.001$ & HS & $<0.001$ & 0.338 & 0.002 \\
\hline 30 & $124.12 \pm 5.50$ & $118.04 \pm 6.20$ & $123.92 \pm 5.61$ & $<0.001$ & HS & $<0.001$ & 0.826 & 0.001 \\
\hline 40 & $123.24 \pm 4.65$ & $120.04 \pm 6.94$ & $124.09 \pm 4.72$ & 0.041 & S & 0.062 & 0.615 & 0.017 \\
\hline 50 & $120.33 \pm 4.04$ & $123.75 \pm 5.36$ & $124.33 \pm 4.07$ & 0.430 & NS & 0.272 & 0.200 & 0.764 \\
\hline 60 & $127.00 \pm 5.65$ & $122.00 \pm 5.65$ & $127.00 \pm 1.41$ & 0.542 & NS & 0.365 & 1.00 & 0.365 \\
\hline $\begin{array}{c}\text { After CO2 } \\
\text { release }\end{array}$ & $124.52 \pm 6.48$ & $122.64 \pm 4.63$ & $124.24 \pm 5.30$ & 0.436 & NS & 0.233 & 0.858 & 0.310 \\
\hline Extubation & $125.60 \pm 8.88$ & $125.40 \pm 3.86$ & $125.12 \pm 6.45$ & 0.967 & NS & 0.914 & 0.796 & 0.880 \\
\hline \multicolumn{2}{|c|}{ Table 3 } & & & \\
\hline
\end{tabular}

As shown in Table 3, all the three groups showed rise in SBP at the time of intubation when compared to baseline, but this was non-significant ( $\mathrm{p}$ value is 0.052 ).

However, this difference was statistically significant between Group B and Group N (p value 0.034), Group F and Group N (p value 0.036 ) and highly significant during 2 to 10 minutes after intubation ( $\mathrm{p}$ value $<0.001$ ).

During the pneumoperitoneum mean SBP in Group B was 130, while in Group F was 116 and 119 in Group N. A decrease in SBP was noted in Group F and Group N during the pneumoperitoneum. Thereafter, it started rising gradually and returned to baseline at the time of extubation. This difference was highly significant statistically ( $\mathrm{p}$ value $<0.001$ ).

A decrease in mean SBP was noted in Group B during extubation with mean SBP 125.60. Mean SBP in Group F was 125.40 and in Group N was 125.12. This difference was statistically non-significant ( $\mathrm{p}$ value $>0.05$ ).

\begin{tabular}{|c|c|c|c|c|c|c|c|c|}
\hline \multirow{2}{*}{ DBP } & Group I & Group II & Group III & \multirow{2}{*}{ P value } & \multirow{2}{*}{ Significance } & \multirow{2}{*}{ B vs. F } & \multirow{2}{*}{ B vs. $\mathbf{N}$} & \multirow{2}{*}{ F vs. $\mathbf{N}$} \\
\hline & Mean \pm S.D & Mean \pm S.D & Mean \pm S.D & & & & & \\
\hline Baseline & $78.24 \pm 7.54$ & $79.76 \pm 5.23$ & $79.40 \pm 5.16$ & 0.655 & NS & 0.380 & 0.502 & 0.835 \\
\hline Intubation & $80.32 \pm 8.80$ & $79.92 \pm 5.00$ & $80.12 \pm 4.14$ & 0.975 & NS & 0.824 & 0.911 & 0.911 \\
\hline 2 & $79.64 \pm 7.35$ & $69.36 \pm 5.35$ & $74.72 \pm 7.49$ & $<0.001$ & $\mathrm{HS}$ & $<0.001$ & 0.013 & 0.007 \\
\hline 4 & $78.64 \pm 9.72$ & $69.52 \pm 3.88$ & $77.92 \pm 5.63$ & $<0.001$ & HS & $<0.001$ & 0.712 & $<0.001$ \\
\hline 6 & $83.96 \pm 10.20$ & $71.88 \pm 4.72$ & $77.24 \pm 6.55$ & $<0.001$ & $\mathrm{HS}$ & $<0.001$ & 0.002 & 0.014 \\
\hline 8 & $88.32 \pm 10.62$ & $72.44 \pm 4.60$ & $76.72 \pm 5.57$ & $<0.001$ & $\mathrm{HS}$ & $<0.001$ & $<0.001$ & 0.045 \\
\hline 10 & $88.88 \pm 7.47$ & $74.80 \pm 3.36$ & $75.88 \pm 5.71$ & $<0.001$ & HS & $<0.001$ & $<0.001$ & 0.510 \\
\hline Pneumo & $91.20 \pm 6.84$ & $73.52 \pm 4.59$ & $78.32 \pm 5.89$ & $<0.001$ & HS & $<0.001$ & $<0.001$ & 0.005 \\
\hline 20 & $84.72 \pm 9.44$ & $78.96 \pm 6.14$ & $77.36 \pm 5.43$ & 0.001 & HS & 0.006 & 0.001 & 0.436 \\
\hline 30 & $81.48 \pm 4.87$ & $77.20 \pm 7.95$ & $76.92 \pm 6.55$ & 0.028 & $S$ & 0.024 & 0.017 & 0.881 \\
\hline 40 & $82.14 \pm 4.38$ & $80.17 \pm 5.49$ & $77.34 \pm 6.63$ & 0.022 & $\mathrm{~S}$ & 0.250 & 0.006 & 0.093 \\
\hline 50 & $93.66 \pm 11.59$ & $83.33 \pm 5.54$ & $78.66 \pm 11.59$ & 0.002 & $\mathrm{HS}$ & 0.010 & $<0.001$ & 0.058 \\
\hline 60 & $95.33 \pm 10.06$ & $89.00 \pm 1.41$ & $83.00 \pm 4.24$ & 0.298 & NS & 0.405 & 0.144 & 0.466 \\
\hline $\begin{array}{c}\text { After } \mathrm{CO} 2 \\
\text { release }\end{array}$ & $81.88 \pm 5.68$ & $81.24 \pm 6.14$ & $81.56 \pm 6.11$ & 0.931 & NS & 0.706 & 0.851 & 0.851 \\
\hline Extubation & $87.08 \pm 5.88$ & $80.72 \pm 5.71$ & $83.16 \pm 5.53$ & 0.001 & $\mathrm{HS}$ & $<0.001$ & 0.018 & 0.135 \\
\hline
\end{tabular}

DBP in all the three groups increased at the time of intubation, but change is non-significant between the three groups (p value is 0.975 ).

Fig. 4 and Table 4 shows DBP in Group B again increases at pneumoperitoneum. This change is highly significant when compared to Group F and Group N ( $p$ value is $<0.001$ ).

Mean DBP in subjects of Group B remained significantly higher from the pneumoperitoneum to 50 minutes after the intubation ( $p$ value $<0.05$ ).

At the time of extubation, mean DBP in Group B, F and N were 87.08, 80.72 and 83.16 respectively. The difference between the means was highly significant statistically ( $p$ value $<0.001$ ).

\begin{tabular}{|c|c|c|c|c|c|c|c|c|}
\hline \multirow{2}{*}{ MAP } & Group I & Group II & Group III & \multirow{2}{*}{ P value } & \multirow{2}{*}{ Significance } & \multirow{2}{*}{ B vs. F } & \multirow{2}{*}{ B vs. N } & \multirow{2}{*}{ F vs. N } \\
\cline { 2 - 7 } & Mean \pm S.D & Mean \pm S.D & Mean \pm S.D & & NS & 0.267 & 0.979 & 0.256 \\
\hline Baseline & $93.76 \pm 5.63$ & $94.96 \pm 5.72$ & $93.72 \pm 4.72$ & 0.653 & NS & 0.868 & 0.268 & 0.345 \\
\hline Intubation & $96.20 \pm 8.37$ & $95.92 \pm 4.60$ & $94.32 \pm 3.85$ & 0.487 & HS & $<0.001$ & 0.001 & 0.041 \\
\hline 2 & $95.28 \pm 6.26$ & $84.52 \pm 5.97$ & $88.48 \pm 7.75$ & $<0.001$ & HS & $<0.001$ & 0.034 & 0.001 \\
\hline 4 & $93.72 \pm 8.60$ & $83.56 \pm 4.27$ & $89.88 \pm 5.15$ & $<0.001$ & HS & $<0.001$ & $<0.001$ & 0.047 \\
\hline 6 & $98.32 \pm 10.33$ & $85.40 \pm 3.81$ & $89.48 \pm 5.61$ & $<0.001$ & & &
\end{tabular}




\begin{tabular}{|c|c|c|c|c|c|c|c|c|}
\hline 8 & $102.12 \pm 10.05$ & $85.88 \pm 4.15$ & $89.84 \pm 4.68$ & $<0.001$ & HS & $<0.001$ & $<0.001$ & 0.044 \\
\hline 10 & $102.76 \pm 6.48$ & $88.08 \pm 3.27$ & $89.72 \pm 4.80$ & $<0.001$ & HS & $<0.001$ & $<0.001$ & 0.253 \\
\hline Pneumo & $104.16 \pm 6.00$ & $87.92 \pm 5.14$ & $92.08 \pm 4.89$ & $<0.001$ & HS & $<0.001$ & $<0.001$ & 0.008 \\
\hline 20 & $98.04 \pm 7.43$ & $91.40 \pm 5.18$ & $92.52 \pm 4.49$ & $<0.001$ & HS & $<0.001$ & 0.001 & 0.500 \\
\hline 30 & $95.72 \pm 3.52$ & $90.80 \pm 6.16$ & $92.60 \pm 4.95$ & 0.003 & HS & 0.001 & 0.031 & 0.207 \\
\hline 40 & $95.90 \pm 3.01$ & $93.52 \pm 4.40$ & $92.91 \pm 4.98$ & 0.057 & NS & 0.043 & 0.542 & 0.146 \\
\hline 50 & $102.67 \pm 8.62$ & $96.83 \pm 3.85$ & $93.91 \pm 3.44$ & 0.013 & S & 0.046 & 0.004 & 0.109 \\
\hline 60 & $109.00 \pm 7.07$ & $100.00 \pm 1.41$ & $97.50 \pm 3.53$ & 0.169 & NS & 0.694 & 0.782 & 0.913 \\
\hline $\begin{array}{c}\text { After CO2 } \\
\text { release }\end{array}$ & $96.12 \pm 4.24$ & $94.96 \pm 445$ & $95.72 \pm 5.16$ & 0.670 & NS & 0.380 & 0.761 & 0.564 \\
\hline Extubation & $99.88 \pm 5.90$ & $95.32 \pm 4.21$ & $97.24 \pm 4.14$ & 0.005 & HS & 0.002 & 0.057 & 0.233 \\
\hline \multicolumn{79}{|c|}{ Table 5 } & & & \\
\hline
\end{tabular}

MAP in all the three groups increased at the time of intubation (Fig. 5 and Table 5), but change is non-significant when compared statistically ( $p$ value is 0.868). At the pneumoperitoneum, mean map in Group B was 104.16, in Group F was 87.92 and in Group N was 92.08. The difference was highly significant statistically ( $p$ value $<0.001$ ). After pneumoperitoneum, mean MAP in Group B is more than
Group N and Group F. This difference is highly significant when compared statistically ( $\mathrm{p}$ value $<0.001$ ).

After $\mathrm{CO} 2$ release, the difference between the mean MAP becomes non-significant statistically ( $p$ value $>0.05$ ).

At the time of extubation, mean MAP in Group B, F and N was $99.88,95.32$ and 97.24 respectively. This difference is highly significant when compared statistically ( $p$ value is 0.005).

\begin{tabular}{|c|c|c|c|c|c|c|c|c|}
\hline PR & $\begin{array}{c}\text { Group I } \\
\text { Mean } \pm \text { S.D }\end{array}$ & $\begin{array}{c}\text { Group II } \\
\text { Mean } \pm \text { S.D }\end{array}$ & $\begin{array}{c}\text { Group III } \\
\text { Mean } \pm \text { S.D }\end{array}$ & P value & Significance & B vs. F & B vs. $\mathbf{N}$ & F vs. $\mathbf{N}$ \\
\hline Baseline & $82.24 \pm 8.84$ & $78.76 \pm 7.36$ & $81.76 \pm 9.43$ & 0.306 & NS & 0.156 & 0.844 & 0.221 \\
\hline Intubation & $82.24 \pm 8.29$ & $80.60 \pm 8.29$ & $82.16 \pm 10.02$ & 0.711 & NS & 0.521 & 0.975 & 0.541 \\
\hline 2 & $84.68 \pm 8.84$ & $79.96 \pm 7.59$ & $79.64 \pm 7.89$ & 0.055 & NS & 0.044 & 0.032 & 0.890 \\
\hline 4 & $87.32 \pm 8.28$ & $80.36 \pm 7.18$ & $77.48 \pm 6.12$ & $<0.001$ & $\mathrm{HS}$ & 0.001 & $<0.001$ & 0.164 \\
\hline 6 & $86.32 \pm 8.72$ & $80.80 \pm 8.48$ & $78.76 \pm 6.37$ & 0.004 & HS & 0.016 & 0.001 & 0.366 \\
\hline 8 & $87.16 \pm 9.28$ & $79.92 \pm 8.58$ & $77.60 \pm 6.78$ & $<0.001$ & HS & 0.003 & $<0.001$ & 0.326 \\
\hline 10 & $87.52 \pm 10.31$ & $81.08 \pm 9.51$ & $78.16 \pm 6.72$ & 0.002 & $\mathrm{HS}$ & 0.013 & $<0.001$ & 0.254 \\
\hline Pneumo & $90.20 \pm 6.99$ & $81.80 \pm 8.75$ & $79.28 \pm 5.35$ & $<0.001$ & $\mathrm{HS}$ & $<0.001$ & $<0.001$ & 0.218 \\
\hline 20 & $86.20 \pm 9.01$ & $78.96 \pm 5.96$ & $77.92 \pm 7.41$ & $<0.001$ & $\mathrm{HS}$ & 0.001 & $<0.001$ & 0.629 \\
\hline 30 & $87.28 \pm 8.28$ & $78.44 \pm 5.76$ & $78.12 \pm 7.11$ & $<0.001$ & $\mathrm{HS}$ & $<0.001$ & $<0.001$ & 0.874 \\
\hline 40 & $86.33 \pm 11.15$ & $80.91 \pm 5.41$ & $78.21 \pm 4.27$ & 0.002 & HS & 0.019 & 0.001 & 0.223 \\
\hline 50 & $83.67 \pm 7.09$ & $77.83 \pm 3.53$ & $78.66 \pm 4.47$ & 0.138 & NS & 0.050 & 0.089 & 0.645 \\
\hline 60 & $85.33 \pm 6.02$ & $82.00 \pm 8.48$ & $80.00 \pm 2.00$ & 0.535 & NS & 0.538 & 0.290 & 0.708 \\
\hline $\begin{array}{c}\text { After CO2 } \\
\text { release }\end{array}$ & $84.60 \pm 10.84$ & $82.80 \pm 6.77$ & $81.48 \pm 5.92$ & 0.401 & NS & 0.437 & 0.179 & 0.568 \\
\hline Extubation & $82.84 \pm 9.17$ & $84.48 \pm 6.36$ & $83.32 \pm 4.97$ & 0.701 & NS & 0.414 & 0.811 & 0.563 \\
\hline \multicolumn{9}{|c|}{ Table 6} \\
\hline
\end{tabular}

As shown in Fig. 6 and Table 6, pulse rate in all the three groups rises at the time of intubation. Mean pulse rate during intubation was 83.24 in Group B, 80.60 in Group F and 82.16 in Group N. This difference was not significant when compared statistically between the groups ( $p$ value is 0.711 ).

Mean pulse rate was higher in Group B at 4 minutes after the intubation and shows an increasing trend till 40 minutes after the pneumoperitoneum. This difference was highly significant when compared between the three groups ( $p$ value $<0.05$ ).

During extubation mean pulse rate in Group B, F and N were $82.84,84.48$ and 83.32 respectively. The difference in the mean pulse rate during extubation was non-significant when compared between the groups ( $p$ value is 0.701 ).

The difference in the post-op SBP, DBP and MAP between different groups was non-significant when compared statistically ( $\mathrm{p}$ value $>0.05$ ).

Mean VAS score in Group B, F and N at 15 minutes postoperatively was $1.44,2.40$ and 2.72 respectively. This difference was highly significant when compared statistically.

VAS score in Group F showed an increasing trend over the next 3 hours. This difference was highly significant statistically when compared with other groups ( $p$ value <
$0.001)$. The reason being short duration of action of fentanyl, 30 - 60 minutes.

At the end of four hours post-operatively, Group B was having VAS score of 4.60, Group F and Group N were having 3.92 and 2.40 respectively. This difference was highly significant when compared statistically ( $p$ value $<0.001$ ).

Sedation score was maximum in the nalbuphine group at 15 minutes post-operatively. This was statistically highly significant when compared to other groups ( $p$ value is 0.001 ). Group N and Group B both showed significant sedation upto 3 hours post-operatively.

\section{DISCUSSION}

Pneumoperitoneum during laparoscopic surgery leads to significant haemodynamic changes such as increase in MAP and systemic vascular resistance and a decrease in cardiac output. These haemodynamic changes can be detrimental due to associated risk of myocardial ischaemia or cerebral haemorrhage; therefore, these should be attenuated.

Rao et al 2013(9) compared butorphanol and fentanyl in patients undergoing laparoscopic surgeries and concluded that no significant difference was observed in systolic blood pressure till 9 minutes after intubation similar to present 
study. Sharma et al (2014)(10) compared the haemodynamic responses to intubation with fentanyl and nalbuphine and concluded that nalbuphine group had significant rise in BP ( $p$ value $<0.05$ ) at the time of intubation when compared to fentanyl in contrast to present where this rise was nonsignificant ( $\mathrm{p}$ value $>0.05$ ). Our results are similar to Balasubramaniam et al(11) (2016) who observed that the DBP after intubation in Group B becomes comparable to the preoperative DBP at the third minute after intubation. The DBP in Group $F$ becomes significantly lower than the preoperative DBP at the tenth minute after intubation. Prasad et al(12) (2016) conducted a comparison between fentanyl and nalbuphine and observed that there is a significant rise in DBP in patients who receive nalbuphine in comparison to those who received fentanyl ( $p$ value $<0.05$ ). Similar results have been noted in the present study as DBP in nalbuphine group is higher than fentanyl group. Verma et al(13) (2006) conducted a study on total intravenous anaesthesia in laparoscopic cholecystectomy and compared butorphanol with fentanyl. They found out that butorphanol and fentanyl both showed a decreasing trend in MAP at the time of pneumoperitoneum when compared to baseline, but this decrease was statistically not significant ( $p$ value $>0.05$ ). However, in the present study Group B depicted an increasing trend in the MAP at the time of pneumoperitoneum. FA Khan et al(14) (2002) compared fentanyl and nalbuphine in total intravenous anaesthesia in laparoscopic cholecystectomy and found a significant increase in heart rate in nalbuphine group (25\%) as compared to fentanyl group ( $\mathrm{p}$ value $<0.05$ ). They concluded that fentanyl provided better haemodynamic stability. In this study, there was no significant difference noted between fentanyl and nalbuphine group in terms of pulse rate changes at the time of intubation and pneumoperitoneum.

Patel et al(15) in 2016 compared intravenous butorphanol with intravenous fentanyl in general anaesthesia and concluded that rise in pulse rate was more in fentanyl group when compared with butorphanol group. The difference between the group was statistically significant for 5 minutes after intubation. Thereafter, it was insignificant for upto 30 minutes. Chawda et al(16) in 2010 stated that patients given nalbuphine $2 \mathrm{mg} / \mathrm{kg}$ showed $4.39 \%$ rise in MAP, which was statistically non-significant. Ahire et al 2016 studied effect of equipotent dose of butorphanol and fentanyl on intraoperative anaesthesia course and postoperative recovery characteristics in laparoscopic surgeries and observed that pain measured by VAS score and requirement of rescue analgesia in postoperative period were found to be lower in patients receiving butorphanol when compared to fentanyl.

Complications like nausea, vomiting, bradycardia, hypotension, chest wall rigidity, pruritus and respiratory depression were recorded.

\section{CONCLUSION}

Sympathetic activation during pneumoperitoneum is attenuated by all the three drugs- Butorphanol, Fentanyl and Nalbuphine. Fentanyl and nalbuphine both were more effective than butorphanol in obtunding the haemodynamic response during pneumoperitoneum. Fentanyl produced even more significant attenuation than nalbuphine.
Nalbuphine and butorphanol both provided good postoperative analgesia and post-operative light sedation without any respiratory depression, adverse effects like nausea and vomiting were infrequent and statistically non-significant.

\section{REFERENCES}

[1] Kataria AP, Attri JP, Kashyap R, et al. Efficacy of dexmedetomidine and fentanyl on pressor response and pneumoperitoneum in laparoscopic cholecystectomy. Anesth Essays Res 2016;10(3):44650.

[2] Acharya G, Gokharu S, Arora KK, et al. Effect of two different doses of dexmedetomidine on hemodynamics in patient undergoing lapaparoscopic surgeries under general anaesthesia - a comparative study. Int J Healthcare Edu \& Med Inform 2016;3(1):12-18.

[3] Bhandari D, Tidke S, Sharma V, et al. Hemodynamic changes associated with laparoscopic cholecystectomy: effect of oral clonidine premedication. IOSR J of Pharmacy 2012;2(4):72-7.

[4] Ahire SS, Laheri V. Study to compare effect of equipotent dose of butorphanol versus fentanyl on intraoperative anaesthesia course and postoperative recovery characteristic in patient undergoing laparoscopic surgery. Int J Res Med Sci 2016;4(9):3838-44.

[5] Sinatra RS, Jahr JS, Watkins-Pitchford JM. The essence of analgesia and analgesics. New York: Cambridge University Press 2011: p. 279.

[6] Fukuda K. Opioid analgesics. In: Miller RD. edr. Miller's Anaesthesia. $8^{\text {th }}$ edn. Philadelphia: Churchill Livingstone/Elsevier 2015: p. 904.

[7] Tariq AM, Iqbal Z, Qadirullah. Efficacy of nalbuphine in preventing haemodynamic response to laryngoscopy and intubation. J Postgrad Med Inst 2014;28(2):211-6.

[8] Samhan Y, Radwan K, Youssef M, et al. Hemodynamic changes and stress response during BIS-guided TCI anesthesia with propofol- fentanyl In laparoscopic versus open cholecystectomy. Egyptian J of Anaesth 2016;32(1):45-53.

[9] Rao MH, Satyanarayana V, Srinivas B, et al. Comparison of fentanyl and butorphanol for balanced anaesthesia in patients undergoing laparoscopic surgeries under general anaesthesia: a prospective, randomised and double blind study. J Clin Sci Res 2013;2:8-15.

[10] Sharma N, Parikh H. A comparative study of hemodynamic responses to intubation: fentanyl versus Nalbuphine. Gujarat Med J 2014;69(2):48-53.

[11] Balasubramaniam S, Revathy J. Comparison of fentanyl and butorphanol in attenuating the haemodynamic responses to laryngoscopy and endotracheal intubation. J Evolution Med Dent Sci 2016;5(99):728893.

[12] Prasad HK, Ramkumar PA, Rajagokilam R, et al. A comparative study of analgesic potential of Nalbuphine versus fentanyl during general anaesthesia. Int $\mathrm{J}$ of Contemporary Med Res 2016;3(10):2815-18. 
[13] Verma R, Jaiswal S, Rao P, et al. Total intravenous anaesthesia in laparoscopic cholecystectomy: comparison of butorphanol and fentanyl. Internet J Anaesthesiology 2006;14(1):1-7.

[14] Khan FA, Hameedullah. Comparison of fentanyl and Nalbuphine in total intravenous anaesthesia (TIVA). J Pak Med Assoc 2002;52(10):459-65.
[15] Patel MH, Kantharia BN. A study on comparison of intravenous Butorphanol with intravenous fentanyl for premedication in general anesthesia. National $\mathrm{J}$ of Med Res 2016;6(1):89-91.

[16] Chawda PM, Pareek MK, Mehta KD. Effect of Nalbuphine on haemodynamic response to Orotracheal intubation. J Anaest Clin Pharmacol 2010;26(4):458-60. 